\title{
Patient and service-related barriers and facitators to the acceptance and use of interventions to promote communication in health and social care: a realist review
}

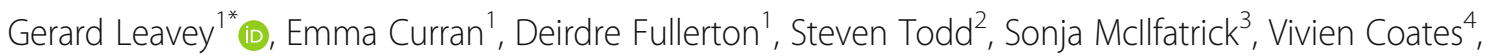
Max Watson ${ }^{5}$, Aine Abbott ${ }^{2}$ and Dagmar Corry ${ }^{1}$

\begin{abstract}
Background: More people living into old age with dementia. The complexity of treatment and care, particularly those with multiple health problems, can be experienced as disjointed. As part of an evaluation of a 'healthcare passport' for people living with dementia we undertook a realist review of communication tools within health and social care for people living with dementia.

Aims: To explore how a 'healthcare passport' might work in the 'real world' of people living with dementia through a better understanding of the theoretical issues related to, and the contextual issues that facilitate, successful communication.

Methods: A realist review was considered the most appropriate methodology to inform the further development and evaluation of the healthcare passport. We undertook a purposive literature search related to communication tools to identify (a) underlying programme theories; (b) published reports and papers on their use in various healthcare settings; (c) evidence on barriers and facliitators of their use.

Results: Communication tools were noted as a way of improving communication and outcomes through: (1) improvement of service user autonomy; (2) strengthening the therapeutic alliance; and (3) building integrated care. However, while intuitively perceived to of benefit, evidence on their use is limited and key barriers to their acceptance and use include: (1) difficulties in clearly defining purpose, content, ownership and usage; (2) understanding the role of family caregivers; and (3) preparation among healthcare professionsals.

Conclusion: Patient-held communication tools may be helpful to some people living with dementia but will require considerable preparation and engagement with key stakeholders.
\end{abstract}

Keywords: Healthcare passport, Dementia, Realist review, Intervention, Design and evaluation [4-10]

\footnotetext{
* Correspondence: g.leavey@ulster.ac.uk

${ }^{1}$ Bamford Centre for Mental Health and Wellbeing, School of Psychology,

Ulster University, Coleraine Campus, Cromore Road, BT52 1 Coleraine, SA,

Northern Ireland

Full list of author information is available at the end of the article
}

(c) The Author(s). 2020 Open Access This article is licensed under a Creative Commons Attribution 4.0 International License, which permits use, sharing, adaptation, distribution and reproduction in any medium or format, as long as you give appropriate credit to the original author(s) and the source, provide a link to the Creative Commons licence, and indicate if changes were made. The images or other third party material in this article are included in the article's Creative Commons licence, unless indicated otherwise in a credit line to the material. If material is not included in the article's Creative Commons licence and your intended use is not permitted by statutory regulation or exceeds the permitted use, you will need to obtain permission directly from the copyright holder. To view a copy of this licence, visit http://creativecommons.org/licenses/by/4.0/ The Creative Commons Public Domain Dedication waiver (http://creativecommons.org/publicdomain/zero/1.0/) applies to the data made available in this article, unless otherwise stated in a credit line to the data. 


\section{Background}

The proportion of people living with dementia is rising $[1,2]$. When dementia is accompanied by multiple and complex health problems, care and treatment can often be experienced as disjointed, with people being moved between services in a somewhat compartmentalised and fragmented process and with limited consultation with patient and their carers [3]. Thus, in the advanced stages of dementia, people may become doubly incontinent, unable to communicate their needs and at increased risk of hospitalisation, following chest and urinary tract infections and frequently experience pain, anxiety and swallowing problems.

The need for greater inter-sectoral and interprofessional care (e.g. between primary care, hospital and hospice) is amplified during episodes of illness and injuries, or where there is accelerated cognitive and functional challenges, adverse events and hospitalisation [4, 5]. Contact with multiple medical services reduces the likelihood of receiving holistic care and diminishes personhood [6] and may encourage disablement and marginalisation [7]. In this context, modern medical care is increasingly regarded as mechanistic and lacking compassion [8]. For example, a person living with dementia may have additional complex health problems such as diabetes and coronary heart disease, and/or may have physical disabilities. In Northern Ireland (NI) these diverse but often connected, problems are managed by different National Health Service (NHS) clinical services. Although health and social care in NI are ostemsibliy itegrated, socal care is sometimes outsourced to private or not-for-profit agencies, creating another layer of service contacts. There is no central coordination of specialist care. Consequently, patients and their families are often distressed by having to attend hospital outpatients on different days and, frequently, being obliged to explain their health problems, history and social contexts to a constantly changing cast of clnicians. The problem of fragmented care is not peculiar to the UK [8]. There is a need, therefore, for communication tools which indicate the needs and preferences of people with complex conditions and which obviate the difficulties of constantly restating health problems to health and socal care professionals. In response, people with chronic and life-limiting conditions, in collaboration with key stakeholder agencies, helped design a 'healthcare passport', maintained by the patient and containing a range of personal and medical information, updated by relevant health and social care professionals. As part of an evaluation of a communication tool (a "healthcare passport") for people living with dementia [9], we undertook a realist review.

\section{Review purpose}

To explore how a communication tool - a 'healthcare passport' - might assist people living with dementia to engage with health and social care providers [9]. To do this we examined the evidence of similar and relevant healthcare communication tools to facilitate a more indepth understanding of potential implementation challenges [9].

\section{Methods}

\section{Realist review}

Realist methodologies increasingly inform the design and evaluation of complex interventions [10], unpacking the relationships between context, mechanism and outcomes of interventions and seeking to understand what works for whom, in what circumstances, and how [10]. Guidance on complex interventions [11] suggest that realist methodologies, can uncover the theories, often tacit, upon which programmes are based. Importantly, complex (active) programmes work only through the knowledge, beliefs, preferences and rationale (interpretation) of various stakeholders, for whom, different things may be at stake [10] . The complexity of dementia and dementia care (e.g. cognitive impairment, commonly occurring co-morbidity, loss of autonomy, and the prominent role of a caregiver proxy), we determined that a realist review was an appropriate method to uncover barriers and facilitators in the use of such tools, and provide insights and recommendations for the implementation of our own communication tool.

We adopted the Realist And MEta-narrative Evidence Syntheses: Evolving Standards.

(RAMESES) standards for realist syntheses frameworks [12] encompassing four interlinked phases including: 1. Programme theory development; 2. Evidence retrieval, data extraction and synthesis; 3 . Programme theory testing and refinement through the evidence synthesis; and 4. Development of actionable recommendations.

\section{Programme theory development}

We undertook an iterative process of consultation with stakeholder groups (service users, family care-givers and health and social care service providers, voluntary and statutory) and discussions within our interdisciplinary team which comprised three academic researchers (social science, social policy and psychology) and six health professionals from general practice, nursing, gerontology, palliative care and mental health. In addition, we held focus groups with service users and carers in order to explore the acceptability, content, and use of the passport. The in-depth discussions were carried out alongside a review of the literature. Following the consultation with stakeholders and the review of previous research on similar concepts, three theory areas 
were identified for greater exploration. These all related to communication approaches that were expected to enhance: 1 ) personhood; 2) integrated care; 3 ) therapeutic alliance and 4) self-management.

\section{Search process}

We used a range of terms related to communication tools and ensured the inclusion of the most relevant material indexed in all major health, social and dementia welfare databases, as well as the grey literature. Keywords were identified through group discussion and previous systematic reviews. Specific 'keywords' varied depending on the database searched. With the support of a Health Sciences Librarian, one of the members carried out searches of six online databases.

The search strategies were kept as broad as possible (see Table 1). Some terms were combined and joined with the Boolean operator 'OR', to capture any instance of any term's use. For example, "dementia" or "Alzheimer's" or "Alzheimer's Disease" and "patient-held records" or "family-held records". Terms referring to communication strategies with the use of a passport were developed and incorporated into search strategies. Searches were completed in May 2016 to cover the years from 2005 to 2015 . We also manually searched the publication references for papers included in systematic reviews. In keeping with the iterative, theory-building approach of realist reviews, we considered qualitative or discussion papers considered as informative to recommendations. In Phase 2, we included a process of evidence retrieval, data extraction and synthesis which involved searching for relevant evidence to test and refine the initial programme theory. In this phase, additional data extraction was carried out from the evidence and sources we identified as relevant. We focussed predominantly on the evidence base related to improving communication in dementia, but also explored the literature on communication interventions in areas (e.g. cancer, palliative care) with similar objectives and features. The consensus of the stakeholder groups was that while the passport should not be focussed on palliative care issues, evidence on advance directives or planning that might illuminate any shared issues related to the passport use. Thus, we also considered papers that addressed the facilitators and barriers associated with such communication tools. The search strategy located systematic and realist reviews, as well as primary studies.

A second team member reviewed the indexing terms and the databases searched, and team members reviewed the final abstracts and papers to ensure that the overall search strategy was executed appropriately.

\section{Inclusion and exclusion criteria}

We included reports of dementia specific workforce, practice and/or organisational development programmes and interventions (combinations of these may vary). Also, included is evidence supporting or rejecting the use of patient-held communication tools in other chronic and life-limiting conditions. Perhaps unique to realist reviews, we did not exclude evidence unless it was unrelated to the identified theories (Fig. 1).

\section{Results}

For the purpose of this realist review we have conceptualised the theoretical construction underlying patient patient-held communication tools. Second, the synthesis of evidence was intended to inform and clarify our understanding about conceptual, instrumental and the direct impact of communication tools.

\section{Theoretical construction of the 'healthcare passport'}

Three overarching theoretical frameworks related to patient-held records or health documents were noted as a way of improving communication and outcomes. First, service user autonomy may be improved; (2) the therapeutic alliance can be strengthened; and (3) integrated care can be achieved, facilitating inter-agency working. Incorporating these concepts as underlying frameworks should affect the three levels of action [10] as prerequisites for successful implementation of a complex intervention. These levels are: (a) at the service user level; (b) at an intrapersonal level and relations between the patient, their informal carers, and clinicians (i.e. the care triad): and (c) patient activation may be promoted at an interpersonal level and at the level where care is organised. Through cross-referencing these three

Table 1 Databases and search terms

\begin{tabular}{|c|c|}
\hline Databases searched & Search terms \\
\hline $\begin{array}{l}\text { Web of Science } \\
\text { Medline } \\
\text { CINAHL } \\
\text { Embase } \\
\text { Psyclnfo } \\
\text { Sociological } \\
\text { Abstracts } \\
\text { Grey literature } \\
\text { Conference } \\
\text { proceedings }\end{array}$ & $\begin{array}{l}\text { healthcare; passport; handheld patient record; healthcare passport; patient-held records; family-held records advance directives; } \\
\text { advance care planning; self-management; dementia; dementia care; Alzheimer's Disease; AD } \\
\text { Communication; communication tools } \\
\text { Personhood; patient-activation; autonomy; therapeutic alliance; care triad; decision making and integrated care }\end{array}$ \\
\hline
\end{tabular}




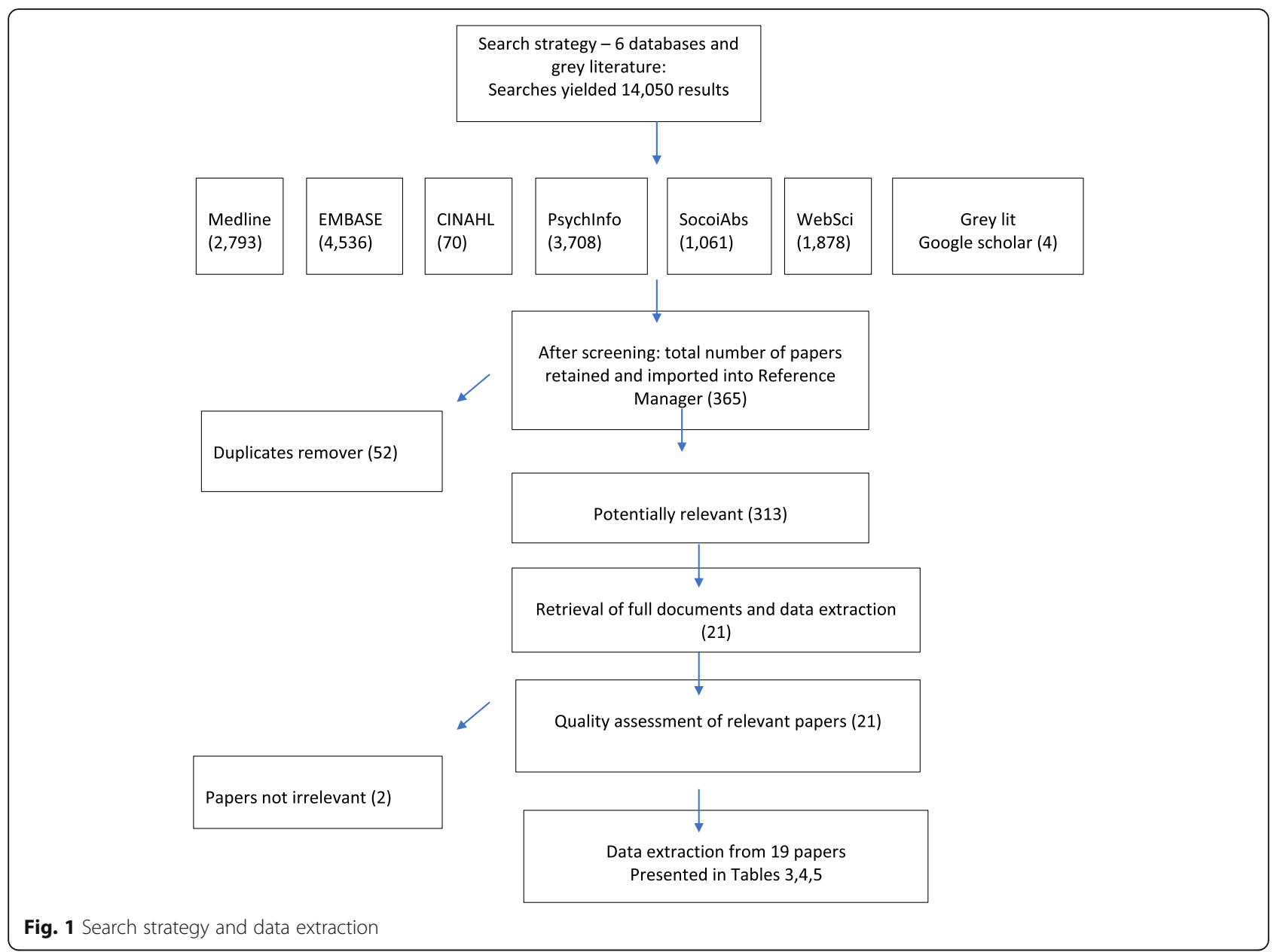

frameworks we highlight the levels of action which may support the 'healthcare passport' and the anticipated outcomes.

\section{Enhancing user autonomy and self-management skills}

The initial framework underlying the 'healthcare passport' is the enhancement of the user's autonomy $[13,14]$. This benefits the person with dementia at an intra-personal level by encouraging active involvement in treatment [14-16], assisting understanding any symptoms and warning signs of deterioration. Importantly, service users feel better supported at both social and organisational levels [17, 18]. Enhanced service user autonomy through improved communication assumes that empowerment is achieved and equal power dynamics will evolve [19, 20] [21]. Moreover, service user autonomy links to the theory of patient activation [22] defined as 'an individual's knowledge, skill, and confidence for managing their health and health care' [22], increasingly important in the context of co-morbidity [23].

Self-efficacy theory, emphasising the importance of an individual's confidence in accomplishing specific goals
[24] [25], is a behaviour-specific psychological attribute which can be learnt or enhanced [25] and may be predicated on individualised coping strategies in dealing with varying task-orientated demands and situational environments [26] [27] [28].

\section{2nd framework: strengthening the therapeutic alliance}

We anticipated that the use of the healthcare passport would strengthen the therapeutic alliance [29] through information exchange between service users and clinical staff [20] which, in turn may increase mutual understanding and treatment compliance [30]. In addition, stakeholders' information needs might be facilitated and shared decision-making may also be promoted [13, 16, $31]$. Consequently, quality of life and quality of care may be improved [32]. At the organisational level, early identification of healthcare problems and timely intervention may be easier to achieve through improved communication, providing that the patient and/or informal carer has been provided with appropriate information. In this way hospital admission may be avoided. However, implicit in the design of the passport is that a meaningful partnership in dementia care is achievable through 
promotion of person-centred care rather than through the more established medical model, the focus of which is on the treatment of individual disease or symptoms decontextualized from social circumstances and environment $[7,33]$.

\section{3rd framework: integrated care}

The third framework is based on integrated care, the 'joined-up' partnership of health care providers. While modern health care systems have invested in electronic sharing of information between health care professionals, they remain limited in their reach. They also exclude the patient and carer from this information exchange. Moreover, while complex, multimorbid conditions and health care contacts require informationexchange and advice to the patient and family caregivers, there are no single platforms to permit this.

The 'healthcare passport' is intended as a tool to assist the co-ordination of care between various health and social care professionals by which the various care needs of the user can be documented and gaps in care avoided $[19,34][35]$. The success of the 'healthcare passport' depends on practitioners' willingness to share information and knowledge, but also requires regular updating when conditions and circumstance change. Clinicians may regard this a burden. There is also an assumption of 'openness' in the entries made by professionals (and by carers) but this may not be the case as it may sometimes involve ethical consideration and degrees of selfcensorship as to what might be helpful or injurious.

\section{Evidence retrieval, data extraction and evidence synthesis} Initial searches provided 14,050 papers. After screening, we imported 362 papers into a database; following removal of duplicates and screening for quality, we identified 310 potentially relevant papers were located. After initial screening, twenty-one papers were quality assessed, data extracted and synthesised in a narrative format. Two of the the 21 papers were deemed by the research team to be irrelevant and were subsequently removed. The final selection comprised thirteen were reviews (systematic or realist reviews), one was an opinion paper, and six reported on evaluations of communication tools for different patient groups. Three of the primary studies described evaluations of tools for people with dementia. Tables 2 and 3 provide a summary of the included reviews, and Table 4 provides details of the primary studies.

Fourteen of the papers described approaches or interventions aimed at improving communication. Two reviews [39, 47] and three primary studies [45, 46, 48] described the evidence on the effectiveness of patient held records with a range of different populations including PLWD, mothers of young children, people with chronic conditions. Two reviews $[36,41]$ examined the research evidence on the advance directives for people with mental illness, and one primary study used an RCT to evaluate the effectiveness of Joint Crisis Planning (JCP). Advanced care planning was examined in a narrative review by Hayhoe et al. [37]. Approaches to improve self-management were the subject of a concept analysis and a review $[38,40]$. Two reviews [42, 49] explored the literature on approaches to improve more integrated care. Table 5 presents a description of some of the approaches described in the reviews and primary studies.

\section{Evidence synthesis}

Shared information and standardised systems between different providers and clinicians, even within the same organisation, are rare or sub-optimally provided. Beyond advanced care directives or planning in palliative care, there are few communication tools such as the 'healthcare passport' for people living with dementia. In other clinical areas where patient held records have been used, the evidence for effectiveness is somewhat limited. Often, it is not a question of the acceptability of PHR but rather, differences between patients and health professionals about their function. In palliative care, the provision and uptake of advance care planning remains limited, stuck as it seems, between widespread theoretical acknowledgement and a pervasive reluctance to use it on religious-ethical (Cultural) grounds. Again, in line with other findings we noted a general failure within dementia studies to apprehend the complexities of living with dementia, and thus, the need for multifactorial interventions to assist communication and effective care [50].

\section{Diagnosis and support}

Healthcare services should continue to address any concerns of people who have been diagnosed with dementia and provide information about symptoms that might be experienced. Literature in this area has identified several common needs that a person with dementia might experience soon after their diagnosis: the need for an explanation; the need to relieve the pressure of maintaining a normal appearance; and the need to feel supported [43]. Unfortunately, the evidence on effective psychological self-management support components is of limited quality [51]. However, minimally, it may be helpful for service providers to develop written care plans or provide a document to convey important information at the time of diagnosis and contact with services [51]. Patients reported being most likely to share such a document with members of their family and many commented on how useful it was to both patients and carers. 


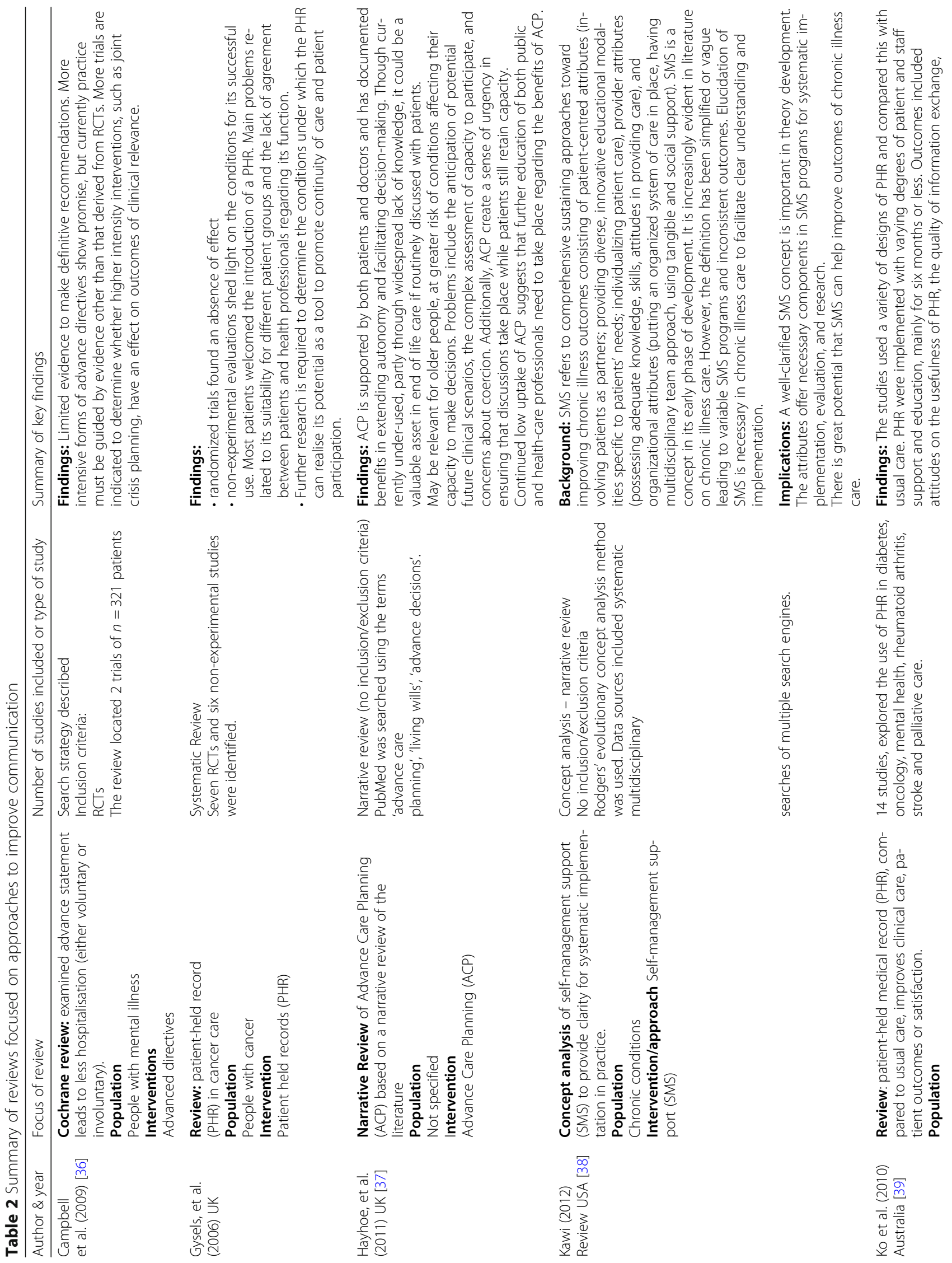




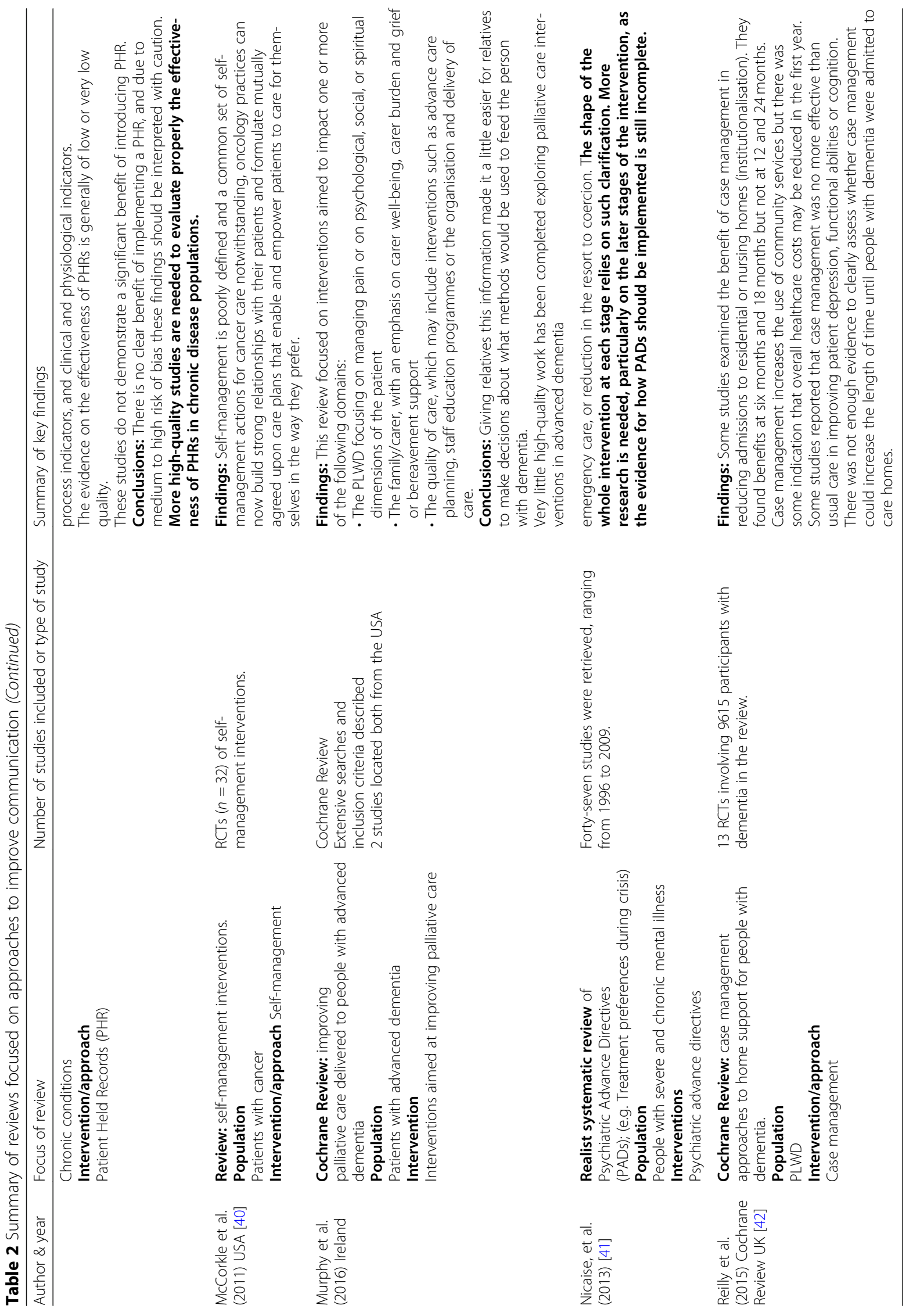



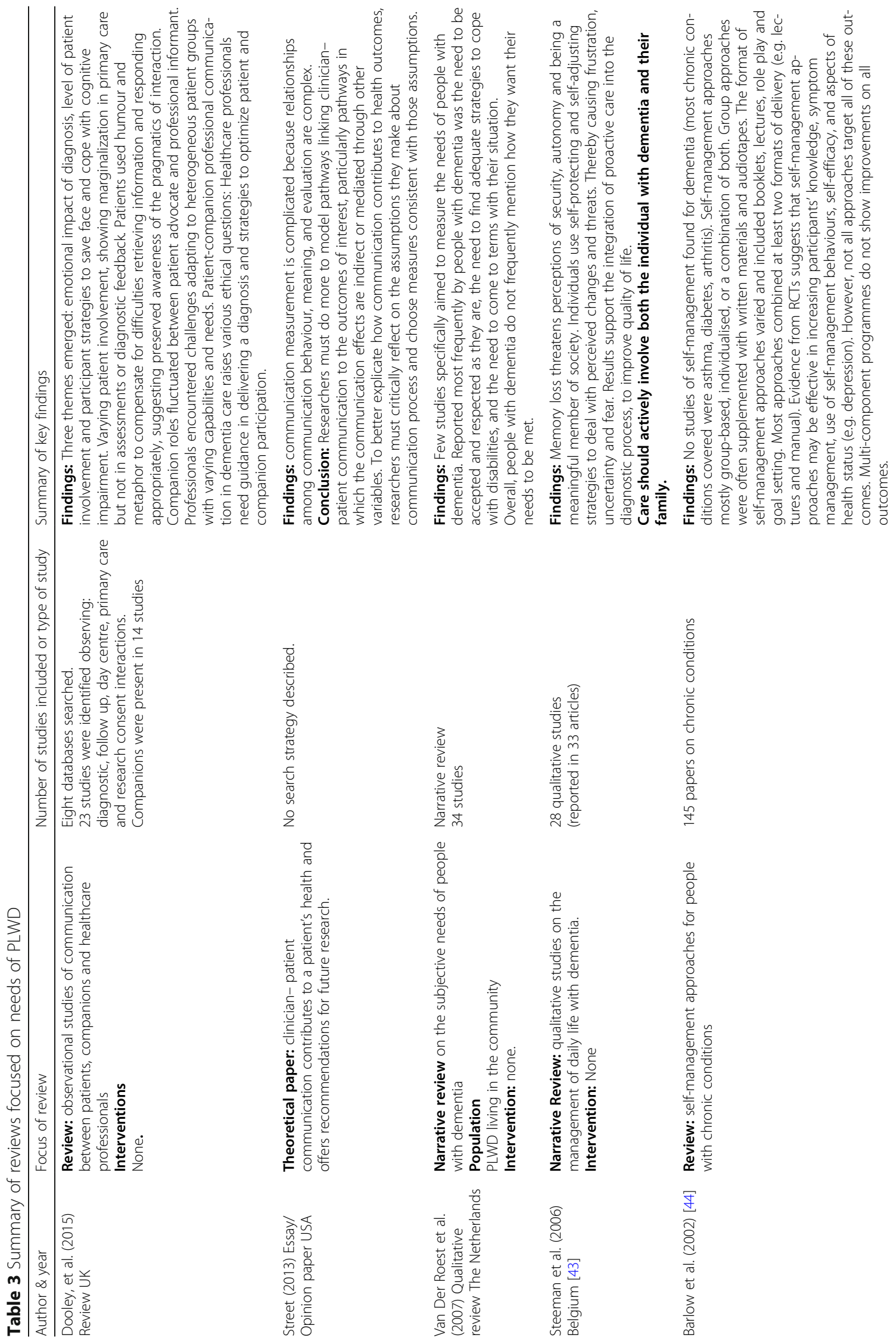

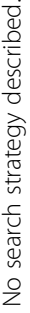

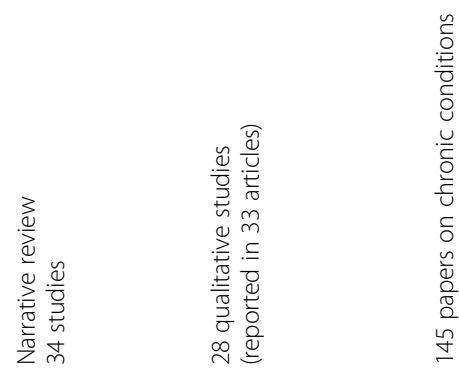

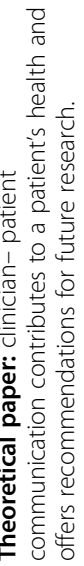

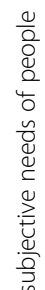

당

哭

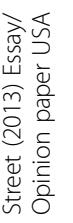

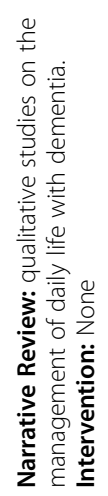

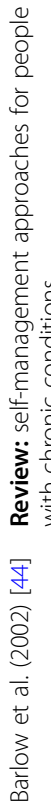




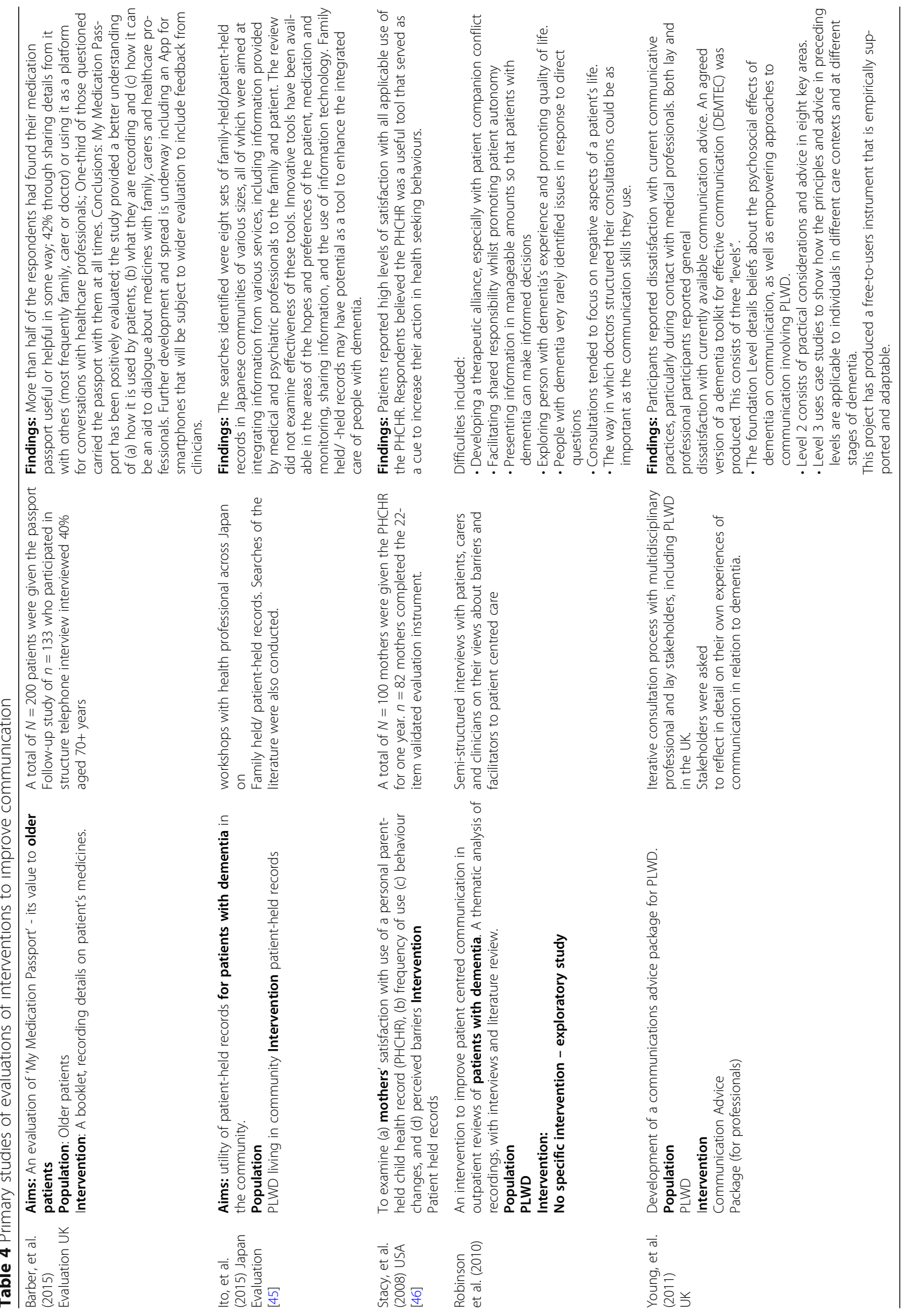




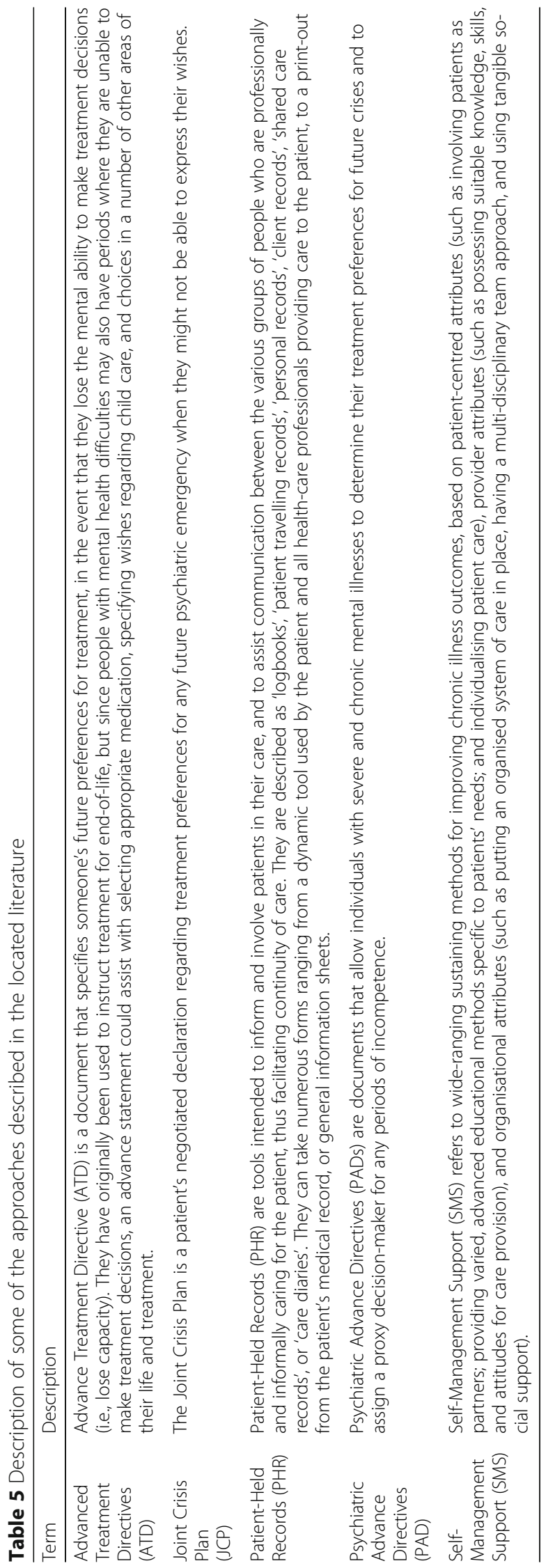




\section{Case-management}

People living with dementia in the UK have typically 4.6 additional long-term medical conditions. Yet, healthcare services are ordinarily structured with a focus on single conditions, rather than taking a whole-person approach. Health care policy in the UK has recommended the introduction of a comprehensive system for case management [52] on a systemic level. Emerging GP commissioning consortia concentrate on authorising more cost-effective models of care for people living with dementia [53], and co-ordinating effective care has been highlighted in recent guidance [54]. A current report has indicated that case management could significantly reduce health-, and social care costs, though the costs of unpaid care are likely to rise regardless [55].

Case management interventions could overcome the difficulties with service fragmentation and ease the burden on carers. However, definitive evidence for case management is elusive given the heterogeneity of diseases, interventions, outcome measures and reporting style [42]. Issues of substitution, and auxiliary information were not always presented in the studies [39]. Therefore, a recommendation for future studies is to demonstrate the extent to which case management interventions were delivered as planned. It is advisable to have well-developed training and protocol manuals to ensure the fidelity and replicability of the intervention [35].

\section{Patient held records}

A review of patient-held records [35] identified 14 eligible studies which included diabetes, oncology, mental health, rheumatoid arthritis, stroke, and palliative care. Bias was notable in most of these, with little evidence that PHRs in these areas are effective. Patients and staff reported no noticeable benefits from the intervention, compared with normal care. Furthermore, in two of the studies staff expressed resistance to using the PHR as a result of an already heavy work load [56, 57]. The contents were often unclear, or combined the PHR with supporting components (e.g., education, intervention coordinators, and/or posters in clinics), and some studies provided a PHR with minimal written instructions on its use. Consequently, it is problematic to identify a 'standard' PHR, even with specific disease areas. Furthermore, the duration of implementation, which was mostly limited to between three and 6 months, is, in many cases, likely to have been inadequate.

To aid the implementation of a PHR, the following changes are worth considering: the form and content of the PHR; attitudes of staff to using the PHR; and attitudes of patients to being proactive in their own care. To increase the success of a PHR intervention, future studies might consider the best application of supporting tools to increase the effectiveness of a PHR. Additional organisational support, such as coordinators, may have mitigated this barrier to implementation in some studies, but are likely to be unavailable in most clinical environments. Staff 'buy-in' and managerial support could impact the outcomes of PHR interventions, but these are not sufficiently described. Notably, most of the reviewed studies showed that patient commitment to the PHR was low.

Formerly, effective use of the PHR was compromised by the low level of engagement from health professionals. It was often not applied by health professionals as intended, i.e., for the sharing of care with patients. Instead, they tended to use it as a means of communication with other professionals rather than with patients. It was found that the PHR served separate functions for health professionals who treated it as a document to confer technical information, and for patients for whom the record represented a means through which to express their values, and views about treatment and future care. In all studies, the PHR was meant to operate both as a clinical and as an informal document, yet the importance of the latter in the management of a patient's care was sometimes overlooked. Despite its patientdriven purpose, health professionals have a key role to play in the acceptance and successful application of the PHR.

We found no publications relating to an evaluation of patient-held (or family-held) records for dementia. However, a review of family-held/patient-held records that were developed in collaboration with psychiatric services patients was undertaken [58] in Japan, where dementia is managed through psychiatric services. The researchers did not evaluate the PHRs but purely sought to report their existence, aims, and content. The aim was to reduce fragmentation-, and improve continuity and coordination of health care.

In an evaluation of a medication passport (MP) [48] most patients reported positive results; feeling that their MP was useful, that it facilitated dialogue about medicines, and that this patient-held portable document was appraised by its users as 'a good idea'. Most patients reported that the passport facilitated communication between them and their health professionals, and carers regarded it as a helpful reference point when communicating with the patient or healthcare professionals [48]. Nevertheless, less than a fifth discussed their passport with their GP, while ownership and application of the passport were unclear.

\section{Advance directives}

As noted earlier, guided by concerns for patient needs and preferences for care, the healthcare passport was originally conceptualised with advance directives in 
mind. A realist systematic review which investigated the use of Psychiatric Advance Directives (PAD) noted various challenges of a complex and multistage intervention $[56,57]$. Although the document was initially intended to promote the patient's autonomy, findings clearly indicated that PADs are more effective in improving the therapeutic alliance. In support of this it has been reported that when enablement features are designed to assist users in completing a PAD or JCP, are practical and responsive to users' interests and needs, it will increase the rates of acceptance and improve the working alliance [59]. Decision making becomes even more difficult when individuals lose the capacity to express their wishes, and in these circumstances health professionals rely on information from others in order to make decisions based on their patients' best interests. Advance care planning should help with making these choices clearer, based on the documented preferences of what the patient would have wanted were their capacity still present. However, such documents are rarely used yet, and where they are, health-care professionals are often cautious due to the potential multitude of ethical and legal problems.

Authors of an RCT focused on joint crisis plans (JCP) concluded that the best measured outcomes were obtained when the designation of the document and its content were discussed among all of those in the care triad [41]. Although the primary use of a PAD intends to enhance the users' autonomy, professional 'buy in' is key to execution. PAD endorsement is higher when professionals play a key role in the development of the document, making them less inclined to override the directives [60]. The designation of a surrogate decisionmaker may assist in the uptake of PAD. However, in some instances, having this designation may unintentionally produce relationship conflict and so weaken the therapeutic alliance.

An operational barrier to the use of PADs is that they have a range of different expectations placed upon them by various stakeholders, most obviously and challengingly the conflicting demands from clinicians and patients, obscuring the purpose and possibly responsible for the low acceptance rate [61]. These expectations need to be clarified at each stage to ensure a successful intervention.

Thus, PADs understood in terms of therapeutic alliance are more feasible than the 'classic PAD'. There are concerns about prescriptive PADs that service users may refuse treatments, and potential conflicts resulting from surrogate decision-making, although these concerns can be addressed when a PAD is completed in consultation with health professionals within a therapeutic alliance framework [59].

A review of 145 self-management interventions for people with chronic conditions [62] did not note any studies in dementia, indicating that the progressive nature of the condition may provoke the perspective that self-management has no relevance. Research in this area is still rare and mostly limited to qualitative design, concept development, and pilot studies for people living with early stage dementia [44, 63]. The synthesis of the evidence on interventions supporting self-management for people with dementia indicates that healthcare services need to provide information about symptoms, and about associated symptoms. This material should also be provided to family and other informal carers [51]. The 'stigma' surrounding dementia and its progressive nature [43] can make discussion about it covert and difficult. The literature identifies a number of shared needs at the time close to a diagnosis of dementia, namely the need for an explanation, the need to relieve the pressure of maintaining a "normal" appearance, and the need to feel supported [59].

Parent-Held Child Health Records (PHCHR) offered to pregnant women and mothers of young children have been used widely for some time. Although employed in a very different area, we wished to examine the factors that made them acceptable and popular over many years [64-68]. Behaviour changes associated with the use of the PHCHR included improvements in: knowing when to call the doctor; keeping appointments; maintaining vaccination schedules; obtaining prenatal care; and staying informed about their own and their child's/children's health. Low uptake was not a concern in this population but the reason provided most frequently for not using the PHCHR was low engagement from staff members. This suggests that the PHCR is held by parents with a clear, central aim of building and safeguarding their child's health at its most vulnerable stage. It is thus, highly focussed and structured towards appointments and key milestones, rather than dealing with multiple concerns and pathology.

\section{Conclusion}

Optimally, health professionals should communicate effectively with patients, patient's families, peers and colleagues consistently throughout the individual's care [69]. Healthcare passports may be helpful to some people living with dementia but as this realist review has demonstrated there are few interventions that attempt to minimise the challenges of fragmented care and poor communication for this population. Moreover, future interventions of this kind must anticipate that access and usage are likely to be affected by multiple and complex factors, including, differential and conflicting stakeholder needs and expectations, professional buy-in, uncertainty of passport aims and functions and the mundane human complications of passivity and forgetfulness. Attention should be paid to the importance of these relationships 
at the different stages of the disease progression in dementia. Thus, while the individual's condition may deteriorate and their needs may become more complex, it should be acknowledged that their environment and social circumstances and support is also likely to undergo change. A patient's needs may be attended to within a delicate ecosystem of various carers, each one reliant on each other and the stability of certain factors and conditions, social and interpersonal; when any one of these factors is disturbed or compromised there are likely to be ramifications for the provision care.

\section{Summary of actionable recommendations}

1. Healthcare passports may be directed for the ultimate benefit of the patient but it should be acknowledged that they will also benefit family members and healthcare professionals.

2. Healthcare passports can only meet their intended utility in a system of relationships. These relationships (stakeholders) should be identified prior to the inception of the passport.

3. Multiple and varying expectations makes the purpose of passport-type interventions unclear and may explain the low take-up rate. Future development of healthcare passports may require a more focussed consideration of their aims, and thus, content.

4. Acceptance of and commitment to the passport from primary care, community and hospital staff is essential. GPs may be particularly pivotal in the success of passports but may be reticent to be involved. This will require high level policy engagement, managerial commitment and additional resources for discussion, consultation and training. HCPs need to be persuaded that the benefits of the passport outweigh the perceived additional staff burden. More generally, the evidence suggests that staff at all levels, including more senior staff, need appropriate training on dementia.

5. A patient's diagnosis of dementia is often not shared with other health professionals and thus may compromise effective care and treatment. A diagnosis of dementia should be flagged up on medical/electronic records. This should include systems for automatic updates of a dementia diagnosis to be transferred to other health-care services that the PLWD.

6. To improve the implementation of healthcare passports (acceptability and usage) there is a need for auxiliary tools such as manuals (e.g. CD-Rom or internet-based) and other explanatory materials. These may require evaluation. Well-developed manuals and protocols should be more widespread, since they can help to ensure the transparency, replicability and integrity of a complex intervention.

7. The ownership and shared use of healthcare passports need to be clarified. To do this, it should be acknowledged that the circumstances, capacities, needs and support, among other things, of individuals are different for each service user and that these factors may also change over time.

8. Families are crucial to the care of people with dementia, especially as the person gets older and the disease progresses. Their role as proxy decisionmaker of the passport is likely to require additional discussion and agreement. Goal-setting and environmental adjustments including carer training in problem-solving strategies were also found to be important components of family carer interventions.

9. The use of models such as the triangle of care model may be helpful in ensuring that the input of family carers is properly recognised. This should include appropriate training in carer engagement for staff, and policy and practice protocols regarding confidentiality and information sharing.

\section{Abbreviations}

AD: Alzheimer's disease; AS: Alzheimer's society; ATD: Advanced treatment directive; EOAD: Early onset alzheimer's disease; EPO: Engagement and participation officer; GP: General practitioner; HCP: Health care professional; HP: Healthcare passport; HSCP: Health and social care professional; JCP: Joint crisis plan; LD: Lewybody dementia; MP: Medication passport;

OT: Occupational therapist; PADs: Psychiatric advance directives; PCC: Person centred care; PD: Parkinson's disease; PHA: Public health agency; PHCHR

: Parent-held child health record; PHR : Patient-held records; PLWD: People living with dementia; QLR: Qualitative longitudinal research; QoC: Quality of care; QoL: Quality of life; RCGP: Royal college of general practitioners; RCT: Randomised controlled trial; SMS: Self-management support; WHSCT: Western health and social care trust

\section{Acknowledgements}

Not applicable.

\section{Authors' contributions}

The study was designed by GL, VC, SMcl, and ST; AA and MW were instrumental in the design of the passport; EC was responsible for data extraction and write-up, DF and DC assisted the realist review. All the authors contributed to the writing of this manuscript. All authors read and approved the final manuscript.

\section{Funding}

This study is funded jointly by the Public Health Agency in Northern Ireland, and Atlantic Philanthropies (January 2015 - October 2017; grant number $\mathrm{COM} / 5017 / 14)$. The funding bodies played no role in the design of the study, the data collection, analysis, interpretation of the data and did not contribute to the writing of the manuscript.

Availability of data and materials Not applicable.

Ethics approval and consent to participate

The project received ethical approval by the Ulster University Ethics Committee (REC reference 15/NI/0129) and was given favourable ethical opinion by the Office for Research Ethics Committees Northern Ireland (ORECNI) on 21 July, 2015. 


\section{Consent for publication}

Not applicable.

\section{Competing interests}

There are no conflicts of interest.

\section{Author details}

'Bamford Centre for Mental Health and Wellbeing, School of Psychology, Ulster University, Coleraine Campus, Cromore Road, BT52 1 Coleraine, SA, Northern Ireland. ${ }^{2}$ Geriatrics, Altnagelvin Area Hospital (WHSCT) Glenshane Road, Londonderry BT47 6SB, Northern Ireland. ${ }^{3}$ School of Nursing, Ulster University, Jordanstown Campus, Newtownabbey BT37 OQB, Northern Ireland. ${ }^{4}$ School of Nursing, Ulster University, Coleraine Campus, Cromore Road, BT52 1SA Coleraine, Northern Ireland. ${ }^{5}$ Adult Services, Northern Ireland Hospice, Whiteabbey Hospital, Doagh Road, Newtownabbey BT37 9RH, Northern Ireland.

\section{Received: 22 December 2018 Accepted: 26 May 2020}

Published online: 04 June 2020

\section{References}

1. Office for National Statistics, Census. First results on population for England and Wales, 2002. London: HMSO; 2001.

2. Ferri CP, et al. Global prevalence of dementia: a Delphi consensus study. Lancet. 2005:366:2112-7.

3. Jahng $\mathrm{KH}$, et al. Preferences for medical collaboration: patient-physician congruence and patient out-comes. Patient Educ Couns. 2005;57:308-14.

4. Trojanowski JQ, et al. A model for improving the treatment and care of Alzheimer's disease patients through interdisciplinary research. Alzheimers Dement. 2012;8(6):564-73.

5. Grant l, et al. Health consequences of Alzheimer's caregiving transitions: effects of placement and bereavement. Psychosom Med. 2002;64:477-86.

6. Kitwood T. The experience of dementia. Ageing Ment Health. 1997;1(1): $13-22$.

7. Kitwood T, Bredin K. Towards a theory of dementia care: personhood and well-being. Ageing Soc. 1992;12:268-87.

8. McCormack B, McCance T. Person-Centred nursing: theory, Models and Methods. Oxford: Blackwell Publishing; 2010.

9. Leavey $\mathrm{G}$, et al. The evaluation of a healthcare passport to improve quality of care and communication for people living with dementia (EQuIP): a protocol paper for a qualitative, longitudinal study. BMC Health Serv Res. 2016;16:363.

10. Pawson $\mathrm{R}$, et al. Realist review - a new method of systematic review designed for complex policy intervention. J Health Serv Res Policy. 2005; 10(1):21-34.

11. Campbell M, et al. Framework for design and evaluation of complex interventions to improve health. Br Med J. 2000:321:694.

12. Wong G, Westhorp G, Buckingham J, Pawson R, Greenhalgh T. RAMESES publication standards: meta-narrative reviews. BMC Med. 2013;11(1):20

13. Srebnik D. Benefits of psychiatric advance directives: can we realize their potential? J Forensic Psychol Pract. 2004;4(4):71-82.

14. Elbogen $E B$, et al. Competence to complete psychiatric advance directives: effects of facilitated decision making. Law Hum Behav. 2007;31(3):275-89.

15. Amering $\mathrm{M}$, et al. Psychiatric wills of mental health professionals: a survey of opinions regarding advance directives in psychiatry. Soc Psychiatry Psychiatr Epidemiol. 1999;34(1):30-4.

16. Papageorgiou A, et al. Advance directives for patients compulsorily admitted to hospital with serious mental disorders: directive content and feedback from patients and professionals. J Ment Health. 2004;13:379-88.

17. Sutherby $K$, et al. A study of 'crisis cards' in a community psychiatric service. Acta Psychiatr Scand. 1999;100(1):56-61.

18. Scheyett AM, et al. Psychiatric advance directives: a tool for consumer empowerment and recovery. Psychiatr Rehabil J. 2007;31(1):70.

19. Backlar $\mathrm{P}$, et al. Consumer, provider, and informal caregiver opinions on psychiatric advance directives. Adm Policy Ment Health. 2001;28(6):427-41.

20. Atkinson JM, et al. Issues in the development of advance directives in mental health care. J Ment Health. 2003;12:463-74.

21. O'Connell MJ, Stein CH. Psychiatric advance directives: perspectives of community stakeholders. Adm Policy Ment Health Ment Health Serv Res. 2005;32(3):241-65
22. Hibbard $\mathrm{JH}$, Cunningham PJ. How engaged are consumers in their health and health care, and why does it matter? Res Brief. 2008:8:1-9.

23. Hibbard $\mathrm{JH}$, et al. Development and testing of a short form of the patient activation measure. Health Serv Res. 2005:40(1):1918-30.

24. Bandura A. Self-efficacy: toward a unifying theory of behavioral change. Psychol Rev. 1977:84(2):191.

25. Bandura A. Social foundations of thought and action: a social cognitive theory. Englewood Cliffs, NJ: Prentice-Hall; 1986.

26. Steffen $A M$, et al. The revised scale for caregiving self-efficacy: reliability and validity studies. J Gerontol Ser B Psychol Sci Soc Sci. 2002;57(1):74-86.

27. Gottlieb BH, Rooney JA. Coping effectiveness: determinants and relevance to the mental health and affect of family caregivers of persons with dementia. Aging Ment Health. 2004;8(4):364-73.

28. Gignac MA, Gottlieb BH. Caregivers' appraisals of efficacy in coping with dementia. Psychol Aging. 1996;11(2):214.

29. Summers RF, Barber JP. Therapeutic alliance as a measurable psychotherapy skill. Acad Psychiatry. 2003;27(3):160-5.

30. Henderson C, et al. Views of service users and providers on joint crisis plans. Soc Psychiatry Psychiatr Epidemiol. 2009;44:369-76.

31. Drake RE, Deegan PE, Rapp C. The promise of shared decision making in mental health. Psychiatr Rehabil J. 2010:34:7-13.

32. Adams JR, Drake RE, Wolford GL. Shared decision-making preferences of people with severe mental illness. Psychiatr Serv. 2007:58:1219-21.

33. Spector A, Orrel M. Using a biopsychosocial model of dementia as a tool to guide clinical practice. Int Psychogeriatr. 2010;22(6):957-65.

34. Swanson JW, et al. Psychiatric advance directives: an alternative to coercive treatment. Psychiatry-Interpers Biol Process. 2000;63:160-72.

35. Fleury MJ, Mercier C. Integrated local networks as a model for organizing mental health services. Admin Pol Ment Health. 2002;30:55-73.

36. Campbell LA, Kisely SR. Advance treatment directives for people with severe mental illnes. Cochrane Database Syst Rev. 2009;(1):CD005963. https://doi. org/10.1002/14651858.CD005963.pub2.

37. Hayhoe B, et al. Advance care planning and the older patient. QJM: Int J Med. 2011;105(3):225-30.

38. Kawi J. Self-management support in chronic illness care: a concept analysis. Res Theory Nurs Pract. 2012;26(2):108-25.

39. $\mathrm{Ko} \mathrm{H}$, et al. Patient-held medical records for patients with chronic disease: a systematic review. Qual Saf Health Care. 2010;9(5):8.

40. McCorkle R, et al. Self-management: enabling and empowering patients living with cancer as a chronic illness. CA: J Cancer Clin. 2011;61(1):50-62.

41. Nicaise $P$, Lorant $V$, Dubois $V$. Psychiatric advance directives as a complex and multistage intervention: a realist systematic review. Health Soc Care Community. 2013;21(1):1-14.

42. Reilly $S$, et al. Case management approaches to home support for people with dementia. London: The Cochrane Library; 2015.

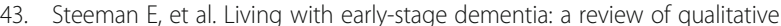
studies. J Adv Nurs. 2006;54(6):722-38

44. Barlow J, et al. Self-management approaches for people with chronic conditions: a review. Patient Educ Couns. 2002:48:177-87.

45. Ito $\mathrm{H}$, et al. Integrating psychiatric services into comprehensive dementia care in the community. Open J Psychiatry. 2015;5(2):129.

46. Stacy RD, Sharma M, Torrence WA. Evaluation of the use of a parent-held child health record by pregnant women and mothers of young children. Calif J Health Promot. 2008:6:138-42.

47. Gysels M, Richardson A, Higginson IJ. Does the patient-held record improve continuity and related outcomes in cancer care: a systematic review. Health Expect. 2007;10(1):75-91

48. Barber S, et al. Evaluation of My Medication Passport: a patient-completed aide-memoire designed by patients, for patients, to help towards medicines optimisation. BMJ Open. 2014;4:e005608. https://doi.org/10.1136/bmjopen2014-005608.

49. Bunn F, et al. Comorbidity and dementia: a mixed-method study on improving health care for people with dementia (CoDem). Health Serv Del Res. 2016;4(8).

50. Dawson A, et al. Evidence of what works to support and sustain care at home for people with dementia: a literature review with a systematic approach. BMC Geriatr. 2015;15:59.

51. Taylor SJ, et al. A rapid synthesis of the evidence on interventions supporting self-management for people with long-term conditions: PRISMS - Practical systematic Review of Self-Management Support for long-term conditions. Health Serv Deliv Res. 2014;2(53). 
52. NICE, Dementia: supporting people with dementia and their carers in health and social care. National Institute for Clinical and Care Excellence. Manchester: National Institute for Health and Care Excellence; 2006.

53. Joint Commissioning Panel for Mental Health. Guidance for commissioners of older people's mental health services. London: JCP-MH; 2012.

54. NICE, Dementia: independence and wellbeing. National Institute for Health and Care Excellence London; 2013.

55. Koch T, et al. The potential of case management for people with dementia: a commentary. Int J Geriatr Psychiatry. 2012;7(12):1305-14.

56. Williams JG, et al. Pragmatic randomised trial to evaluate the use of patient held records for the continuing care of patients with cancer. Qual Health Care. 2001;10:159-65.

57. Finlay IG, Wyatt P. Randomised cross-over study of patient-held records in oncology and palliative care. Lancet. 1999;353:558-9.

58. Wright MO, et al. The electronic medical record as a tool for infection surveillance: successful automation of device-days. Am J Infect Control. 2009:37(5):364-70.

59. Street, RL, Gordon,H, Haidet, P. Physicians' communication and perceptions of patients: is it how they look, how they talk, or is it just the doctor? Soc Sci Med 2007;65(3): 586-598.

60. Ito $\mathrm{H}$, et al. Evaluation of My Medication Passport: a patient-completed aidememoire designed by patients, for patients, to help towards medicines optimisation. BMJ Open. 2014;4(8).

61. Nicaise P, et al. Users' and health professionals' values in relation to a psychiatric intervention: the case of psychiatric advance directives. Adm Policy Ment Health. 2015;42:384-93.

62. Thornicroft $\mathrm{G}$, et al. Clinical outcomes of joint crisis plans to reduce compulsory treatment for people with psychosis: a randomised controlled trial. Lancet. 2013;381:16341641.

63. Van Dorn RA, et al. Clinicians' attitudes regarding barriers to the implementation of psychiatric advance directives. Adm Policy Ment Health Ment Health Serv Res. 2006;3(4):449-60

64. Martin F, et al. Perceived barriers to self-management for people with dementia in the early stages. Dement Geriatr Disord. 2013;12:481-93.

65. Martin F, et al. Qualitative evaluation of a self-management intervention for people in the early stage of dementia. Dementia. 2015;14:418-35.

66. Bjerkeli Grøvdal L, Grimsmo A, Ivar Lund Nilsen T. Parent-held child health records do not improve care: a randomized controlled trial in Norway Scand J Prim Health Care. 2006;24(3):186-90.

67. Campbell $\mathrm{H}$, Halleran J. An evaluation of the personal child health record in fife. Health Bull. 1993;51(6):399-406.

68. O'Flaherty S, et al. Personal health records: an evaluation. Arch Dis Child 1987;62(11):1152-5.

69. Volkmer RE, Gouldstone MA, Ninnes CP. Parental perception of the use and usefulness of a parent-held child health record. J Paediatr Child Health. 1993;29(2):150-3.

\section{Publisher's Note}

Springer Nature remains neutral with regard to jurisdictional claims in published maps and institutional affiliations.

Ready to submit your research? Choose BMC and benefit from:

- fast, convenient online submission

- thorough peer review by experienced researchers in your field

- rapid publication on acceptance

- support for research data, including large and complex data types

- gold Open Access which fosters wider collaboration and increased citations

- maximum visibility for your research: over $100 \mathrm{M}$ website views per year

At $\mathrm{BMC}$, research is always in progress.

Learn more biomedcentral.com/submissions 